\title{
Comprehensive Neuropsychological Assessment of Cognitive Functioning of Adults With Lower Limb Amputation in Rehabilitation
}

Article in Archives of Physical Medicine and Rehabilitation · August 2018

DOI: 10.1016/j.apmr.2018.07.436

CITATION

1

6 authors, including:

Richard Lombard-Vance

National University of Ireland, Maynooth

17 PUBLICATIONS 38 CITATIONS

SEE PROFILE

Deirdre Desmond

National University of Ireland, Maynooth

66 PUBLICATIONS 1,094 CITATIONS

SEE PROFILE

Some of the authors of this publication are also working on these related projects:

Children's participation in shared decision making View project

Neuropsychological outcome and quality of life following childhood stroke View project
Fiadhnait O'Keeffe

St. Vincents University Hospital

41 PUBLICATIONS 691 CITATIONS

SEE PROFILE

Pamela Gallagher

Dublin City University

123 PUBLICATIONS 2,052 CITATIONS

SEE PROFILE 


\section{Accepted Manuscript}

Comprehensive Neuropsychological Assessment of Cognitive Functioning of Adults with Lower Limb Amputation in Rehabilitation

Richard Lombard-Vance, PhD, Fiadhnait O'Keeffe, PhD, DClinPsy, Deirdre Desmond, $\mathrm{PhD}$, Robert Coen, PhD, Nicola Ryall, MB BCh BAO, FRCPI, Pamela Gallagher, PhD

PII: S0003-9993(18)31172-9

DOI: $\quad$ 10.1016/j.apmr.2018.07.436

Reference: YAPMR 57348

To appear in: ARCHIVES OF PHYSICAL MEDICINE AND REHABILITATION

Received Date: 8 May 2018

Revised Date: 17 July 2018

Accepted Date: 19 July 2018

Please cite this article as: Lombard-Vance R, O'Keeffe F, Desmond D, Coen R, Ryall N, Gallagher P, Comprehensive Neuropsychological Assessment of Cognitive Functioning of Adults with Lower Limb Amputation in Rehabilitation, ARCHIVES OF PHYSICAL MEDICINE AND REHABILITATION (2018), doi: 10.1016/j.apmr.2018.07.436.

This is a PDF file of an unedited manuscript that has been accepted for publication. As a service to our customers we are providing this early version of the manuscript. The manuscript will undergo copyediting, typesetting, and review of the resulting proof before it is published in its final form. Please note that during the production process errors may be discovered which could affect the content, and all legal disclaimers that apply to the journal pertain. 


\section{Comprehensive Neuropsychological Assessment of Cognitive Functioning of Adults with Lower Limb Amputation in Rehabilitation}

Richard Lombard-Vance, $P h D^{1,2}$

Fiadhnait O'Keeffe, PhD, DClinPsy ${ }^{2,3}$

Deirdre Desmond, $P h D^{2,4}$

Robert Coen, $P h D^{5}$

Nicola Ryall, $M B$ BCh $B A O, F R C P I^{2,3}$

Pamela Gallagher, $P h D^{1,2}$

1: School of Nursing and Human Sciences, Dublin City University, Dublin, Ireland

2: Dublin Psychoprosthetics Group, Dublin, Ireland

3: Department of Psychology, National Rehabilitation Hospital, Dún Laoghaire, Co. Dublin, Ireland

4: Department of Psychology, Maynooth University, Maynooth, Co. Kildare, Ireland

5: Mercer's Institute for Research on Ageing, St James's Hospital, Dublin, Ireland 


\section{Funding}

Funded by an Irish Research Council Postgraduate Research Scholarship and a Dublin City University Daniel O’Hare Postgraduate Studentship provided to Richard Lombard-Vance.

\section{Presentation}

Preliminary findings were previously presented in part at the International Society for Prosthetics and Orthotics World Congress, June 2015, Lyon, France.

\section{Acknowledgements}

The authors would like to acknowledge Gillian Murphy, and the National Rehabilitation Hospital clinical (in particular physiotherapy and occupational therapy) and administrative staff for their assistance with data collection.

\section{Conflicts of Interest}

The authors have no conflicts of interest to declare:

We certify that no party having a direct interest in the results of the research supporting this article has or will confer a benefit on us or on any organization with which we are associated AND, if applicable, we certify that all financial and material support for this research (e.g., NIH or NHS grants) and work are clearly identified in the title page of the manuscript.

\section{Corresponding Author}


Prof. Pamela Gallagher

School of Nursing and Human Sciences,

Dublin City University,

Glasnevin,

Dublin 9,

Ireland

Tel.: 017008958

Email.: pamela.gallagher@dcu.ie 


\section{Comprehensive Neuropsychological Assessment of Cognitive}

\section{Functioning of Adults with Lower Limb Amputation in Rehabilitation}

Objective: To establish a comprehensive profile of cognitive functioning in people engaged in lower limb amputation (LLA) rehabilitation.

Design: Cross-sectional study as part of a longitudinal prospective cohort.

Setting: A national, tertiary, rehabilitation hospital.

Participants: Adult volunteer participants $(\mathrm{N}=87)$ referred for comprehensive rehabilitation for major LLA were sampled from 207 consecutive admissions. Participants with both vascular $(n=69)$ and non-vascular $(n=18)$ LLA aetiologies were included.

\section{Interventions: Not applicable}

Main Outcome Measure(s): Demographic and health information, and a battery of standardised neuropsychological assessments

Results: Compared to normative data, impairment was evident in overall cognitive functioning ( $p \leq .003)$. Impairment was also evident in particular areas, including reasoning, psychomotor function, information processing, attention, memory, language/naming, visuospatial functions, and executive functions (all $p \leq .003$ Holm-corrected). There were also higher frequencies of impaired functions across most aspects of functioning in this group, compared to expected frequencies in normative data ( $p \leq .003$ Holm-corrected). There were no significant differences in cognitive functioning between participants of vascular and nonvascular LLA aetiology. 
22 Conclusions: Findings support the need for cognitive screening at rehabilitation admission

23

24

25 in this area.

29 Key Words: Amputation; cognition; lower extremity; neuropsychology; rehabilitation regardless of aetiology. Administration of comprehensive neuropsychological assessment with a battery sensitive to vascular cognitive impairment is recommended in some cases, to generate an accurate and precise understanding of relative strengths and weaknesses in cognitive functioning. Cognitive functioning is a potential intervention point for improvement of rehabilitation outcomes for those with LLA and further research is warranted research 


\section{List of abbreviations}

33

34

35

36

37

- BADS: Behavioural Assessment of the Dysexecutive Syndrome

- CVLT-II SF: California Verbal Learning Test II Short Form

- D-KEFS: Delis Kaplan Executive Function System

- FrSBe: Frontal Systems Behavior Scale - self-rated

- LLA: lower limb amputation

- MCI: mild cognitive impairment

- MoCA: Montreal Cognitive Assessment

- PVD: peripheral vascular disease

- RBANS: Repeatable Battery for the Assessment of Neuropsychological Status

- TEA: Test of Everyday Attention

- VCI: vascular cognitive impairment

- VOSP: Visual Object and Spatial Perception Battery

- WAIS-IV: Wechsler Adult Intelligence Scales-IV

- WMS-IV: Wechsler Memory Scale-IV 
In economically developed countries, most major lower limb amputations (LLA) result from dysvascularity, i.e. peripheral vascular disease (PVD) and diabetes mellitus ${ }^{1}$. People with LLA (PwLLA) are at greater risk of having or developing impaired cognitive functioning ${ }^{2}$, with high prevalence of dysvascularity as a precipitating factor in LLA likely underlying this risk. PVD is a marker for generalised cardiovascular and cerebrovascular pathology, and has been linked to impaired cognitive functioning and vascular cognitive impairment (VCI) ${ }^{3-5}$. Overall cognitive functioning, processing speed, attention, immediate and delayed memory, naming, visuospatial construction, and executive functions are impaired in VCI ${ }^{6}$. Diabetes has been associated with a similar profile of impairment ${ }^{7}$. Furthermore, the increasing age at which most LLA are carried out itself presents increasing risk of cognitive impairment and dementia ${ }^{8}$. In essence, LLA risk factors - dysvascularity and advanced age - are shared risk factors for cognitive impairment. Impaired cognitive functioning may explain a proportion of the variance in rehabilitation outcomes ${ }^{9}$; yet relatively little research has considered cognitive functioning in PwLLA ${ }^{2}$. While there is some evidence of impaired memory ${ }^{10}$, information processing ${ }^{11}$, and executive functioning deficits ${ }^{10,11}$ in PwLLA, a comprehensive understanding has been hampered by limitations of methodology and scope of the extant research literature.

Profiles of cognitive functioning are heterogeneous; people have variable relative strengths and weaknesses across different aspects of functioning, the degree of such strengths and weaknesses also varies. Most previous research however has relied on simple categorical definitions of cognitive functioning (e.g. ${ }^{12-16}$ ), including unspecified dementia diagnoses, rather than standardised neuropsychological assessment. This approach neglects the range of functioning in the LLA population, ultimately limiting understanding of the range of potential contributors to rehabilitation outcomes. Furthermore, studies examining cognitive profiles have generally used cognitive screens or narrow assessment batteries, which do not capture 
the breadth of functioning or are insensitive to $\mathrm{VCI}{ }^{10,17,18}$. In some cases, reporting was not sufficient to make determinations regarding the profile ${ }^{12,18}$. Drawing conclusions from other studies is limited by sample sizes or research designs that preclude generalisation ${ }^{11,19}$. Comparisons between patients of vascular and non-vascular LLA aetiology are also lacking, limiting our understanding of the general profile of functioning in the LLA rehabilitation population.

Recent work with a large sample with LLA ( $=1086)$ examined self-reported cognitive concerns (i.e. difficulties in functioning) ${ }^{20}$. Respondents reported significantly more cognitive concerns than a general population normative sample, regardless of age or aetiology. However, self-report and third party observation may not be reliable indicators of cognitive functioning. Persons with executive functioning difficulties may lack insight into their own cognitive functioning and behaviour. Additionally, difficulties with aspects of cognitive functioning can be masked, for example by intact language production skills. With greater scope than cognitive screens, comprehensive neuropsychological assessment can elucidate the breadth and depth of cognitive strengths and weaknesses, thus assisting treatment or rehabilitation planning ${ }^{21}$.

The purpose of this study was to generate a comprehensive neuropsychological profile of people who attended rehabilitation at a national rehabilitation hospital following LLA. The aim was to describe cognitive functioning in terms of a) whether LLA rehabilitation participants' assessment scores differed from normative means, and b) the proportions of the sample with scores in the borderline or impaired ranges of functioning. Cognitive functions assessed included overall cognitive functioning, reasoning, psychomotor speed, information processing, attention, memory, visuospatial perception and construction, language, and executive function, as well as estimated premorbid intellectual ability. A 
secondary aim was to investigate differences between participants with vascular and nonvascular aetiologies.

\section{Methods}

\section{Design}

This cross-sectional study forms part of a longitudinal prospective cohort study investigating cognitive functioning and rehabilitation outcomes in PwLLA enrolled in a comprehensive LLA rehabilitation programme at a Commission for Accreditation of Rehabilitation Facilities (CARF) -accredited rehabilitation hospital.

\section{Participants}

Inclusion criteria were: presence of a major LLA (i.e. unilateral or bilateral from ankle to hip level), English language fluency, age $\geq 18$ years. Exclusion criteria were: major upper limb amputation (i.e. wrist disarticulation or above; participants with transphalangeal or partial hand amputation were not excluded provided they could manipulate assessment materials), or being too medically unwell.

Eighty-seven participants were recruited. Of 207 consecutive admissions over two years, 3 were excluded as medically unwell, 1 was non-English speaking, and 116 declined. Participants gave written, informed consent prior to participation. The hospital's Ethics Committee approved this research. 


\section{Measures}

120 Demographic and clinical data were collected from healthcare records. Distress was assessed using Hospital Anxiety and Depression Scale total scores ${ }^{22,23}$. The battery of standardised neuropsychological assessments was selected to provide a comprehensive profile of cognitive functioning and impairment, be sensitive to VCI, and limit burden on participants. It and aspects of cognitive functioning examined are noted in table 2. Higher scores indicate higher levels of functioning, with exception of the Frontal Systems Behaviour Rating Scale (FrSBe), for which lower scores indicate better self-rated functioning. All measures were age standardised, with the FrSBe also gender normed.

\section{Procedure}

130 The majority of participants engaged in at least two assessment sessions, lasting on average 50 minutes. Where timetables allowed, sessions up to approx. 110 minutes with a short break in the middle were conducted. Sessions continued until the battery (approx. 3.5 hours) was completed, or discontinued due to participants declining further participation, limitations on timetable availability, or early discharge from rehabilitation. Assessments were undertaken while participants were engaged in a busy rehabilitation programme, and were delivered across sessions in an order that minimised the risk of assessments interfering with each other. As completion rates differed, the order of test administration was altered to prioritise completion of measures of overall cognitive functioning in the first instance (e.g. RBANS), then measures tapping into each of one of the following domains: attention, memory, executive function, and then the remainder of the battery. Some assessments were completed as part of routine clinical assessment. Participants were referred to a senior clinical 
neuropsychologist (FOK) if they requested feedback on assessments or in instances of distress.

\section{Analysis}

146 To examine relationships between demographic and clinical variables and neuropsychological assessments, including whether scores differed between vascular and nonvascular amputation aetiologies, independent samples t-tests, Mann-Whitney U tests, and Spearman rho correlations were used. In assessing whether LLA rehabilitation participants' assessment scores differed from normative means, one-sample t-tests were used. Sample means were compared against the means and standard deviations of published normative values for each assessment. Similar analyses have been used previously ${ }^{20,24}$, and allow for an inferential estimation of whether and how cognitive functioning in (this whole sample of) PwLLA differs from the general population.

To estimate the proportions of PwLLA in rehabilitation programmes that might require particular rehabilitative attention due to difficulties with various aspects of cognitive functioning, separate chi-square analyses investigated with the distribution of scores at each of three levels (where normative values were available). The levels were impaired $(\mathrm{z} \leq-2.0$; scale scores $1-3 ; \leq 2^{\text {nd }}$ percentile), borderline $\left(-1.99 \leq \mathrm{z} \leq-1.5\right.$; scale scores $4-5 ; \leq 7^{\text {th }}$ percentile approx.) and not impaired. This classification of 'impairment' is used in the Wechsler classification system $^{25}$; the $\mathrm{z}=-1.5$ borderline classification has been used in studies of mild cognitive impairment (MCI) ${ }^{26-28}$. Two assessments were exceptions: FrSBe $^{29}$ (borderline: $60 \geq \mathrm{T} \leq 64$; impaired: $\mathrm{T} \geq 65$ ) and VOSP Position Discrimination (borderline: raw score 18/20; impaired: raw score $\leq 17 / 20$ ). 
166

Holm's method of correction for multiple comparisons ${ }^{30,31}$ was employed on a

family-wise basis. Effect sizes reported are Cohen's $d$ (small $\geq .2$, medium $\geq .5$, large $\geq .8$ ). Data

were analysed with IBM SPSS Statistics version 21.

\section{Results}

170 Sample demographic and clinical characteristics are summarised in Table 1. Participants with dysvascular LLA (PVD or diabetes) were significantly older ( $\mathrm{n}=69, \mathrm{M}=62.93, \mathrm{SD}=12.02$, range $=33-86)$ than the non-vascular group $(\mathrm{n}=18, \mathrm{M}=41.89, \mathrm{SD}=15.13$, range $=21-73)$ $(t(85)=6.26, p<.001)$. Groups did not differ in education, gender, marital status, amputation level, number of comorbidities, distress, or length of stay. The sample was slightly younger than the group of all potential participants attending LLA rehabilitation at the recruitment site (annual M=60 to 63 during recruitment years). Other demographic or clinical information of non-participants was not available. evident in the significantly lower performance of the sample on the clear majority of aspects of cognitive functioning assessed relative to normative means. Results of this main analysis 
are summarized in table 2 , which also provides information on normative means and standard

deviations for reference. This sample did not differ from the normative population in

estimated premorbid intellectual ability. Overall cognitive functioning was significantly

lower (RBANS Total Index; $d=-.9$ ), and the mean MoCA score of 22.9 (SD=3.99) was below

the cut-off $\left(<24^{32}\right)$ for suspected cognitive impairment. The sample scored significantly

lower on all three reasoning assessments $(d \leq-.52)$ and on psychomotor speed $(d=-.72)$. For

information processing, significantly lower scores were evident on colour-naming (D-KEFS

Color-Word Interference Condition 1(Colour Naming), $d=-.7$ ), and difficult, time-pressured

tasks (RBANS Coding, $d=-1.25$; WAIS-IV Symbol Search, $d=-1.03$ ), but not word reading

(D-KEFS Color-Word Interference Condition 2 (Word Reading), $d=-.29$ ). All assessments of focused and sustained attention were significantly lower (-.69 $\geq d \geq-1.45)$, but differences in attention span and divided attention were non-significant (RBANS Digit Span, $d=.12$; TEA

Telephone Search While Counting, $d=-.22)$. Both immediate list learning scores were significantly lower (-.42 $\geq d \geq-.8)$. The sample fared better on immediate story memory, with a non-significant difference on a shorter story (RBANS Immediate Story Memory, $d=-.24$ ), and a significant difference of small effect size for longer stories (WMS-IV Logical Memory I, $d=-.47)$. There was no significant difference in recall after a 1 minute delay following four trials of a verbal list (CVLT-II SF short delay free recall, $d=-.3$ ). All aspects of recall after longer delays (circa $20+$ minutes), were significantly lower (-.44 $\geq d \geq-.73)$. Delayed recognition scores were also significantly lower (RBANS List Recognition, $d=-.58$ ), even when cues were provided (CVLT-II SF cued recall, $d=-.84$ ). No difference was evident in confrontational naming of everyday objects (RBANS Naming, $d=-.23$ ). The GNT included less common items, and the mean raw score $(16.95, \mathrm{SD}=6.44)$ corresponded to approximately the $25^{\text {th }}$ percentile. Participants fared better on visuospatial perception (VOSP Position 
.17 ) than construction (RBANS Figure Copy, $d=-.54)$. Of the core aspects of executive functioning, significantly lower scores were evident in inhibition (D-KEFS Color-Word Interference Condition 3 (Color-Word Switching), $d=-.76$ ), cognitive flexibility (D-KEFS Trail Making Test Condition 5 (Number-Letter Switching), $d=-1.05)$, and all aspects of verbal fluency ($.42 \geq d \geq-.72$ ). Working memory, which did not differ, was an exception (WAIS-IV Digit Span, $d=-.15$, ns). The planning (BADS Zoo Map) mean score corresponded to borderline impaired functioning. Self-rated executive and frontal lobe dysfunction (including apathy, behavioural disinhibition, dysexecutive functioning) was significantly higher (FrSBe Self-Rated Total, $d=.59$ ).

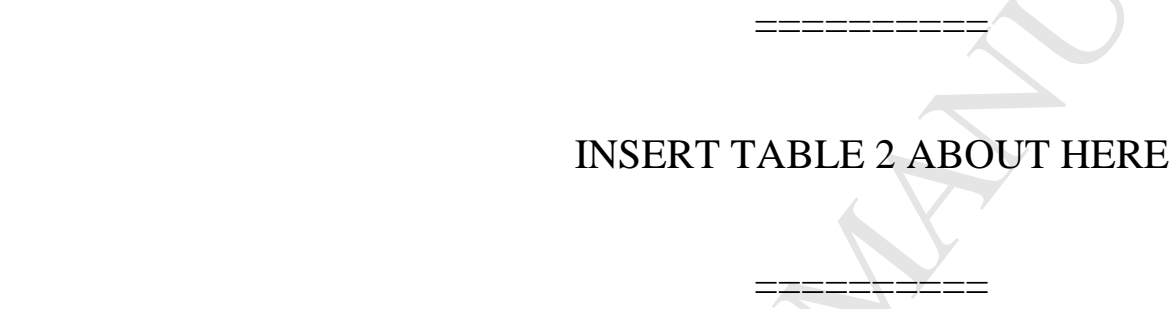
Significantly higher proportions of the sample had borderline and impaired scores compared to normative populations across the cognitive functioning spectrum (see table 3 ). This included overall cognitive functioning (RBANS Total Index, 34\% of scores), visual abstract reasoning (WAIS-IV Matrix Reasoning, 21\%), psychomotor speed (D-KEFS Trail Making Test Condition 5 (motor speed), 19\%), and complex, time pressured information processing (RBANS Coding, 58\%; WAIS-IV Symbol Search 33\%). This was also the case for all aspects of attention (range $=11-41 \%$ ) except divided attention, all aspects of immediate and delayed memory (range=21-41\%), confrontational naming (RBANS Naming, 17\%), visuospatial perception (line orientation, 22\%), and construction (figure copy, 43\%). Similar results were found for a range of executive functions including inhibition (38\%), cognitive flexibility (47\%), and verbal fluency (category and phonemic, 19-23\%). Additionally, a 
significantly higher proportion had scores in the borderline or extremely low range for estimated premorbid intellectual functioning (WTAR, 22\%). 52.6\% of MoCA scores fell at or below the selected cut off $(<24)$. The VOSP Position Discrimination task was failed by $28 \%$ of those who completed the measure. For planning (BADS Zoo Map), $88 \%$ of scores were in the borderline or impaired ranges. FrSBe self-ratings were above the threshold for executive and frontal lobe dysfunction (including apathy and behavioural disinhibition) for $45.5 \%$ of those who completed the measure.

\section{INSERT TABLE 3 ABOUT HERE}

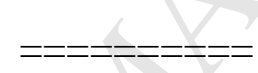

Mann-Whitney U tests indicated no significant differences in assessment scores between aetiology groups (scores for the vascular and non-vascular groups are provided in table 3 for comparative purposes, with additional information in table $\mathrm{S} 1$ [online supplement]). Amputation level, length of stay, marital status, and distress (HADS) were unrelated to test scores. Older age was significantly related to lower MoCA $\left(r_{\mathrm{s}}=-.503\right.$, $p<.001$ ) and lower RBANS Line Orientation (visuospatial perception, $r_{\mathrm{s}}=-.443, p<.001$ ) scores. More comorbidities (dichotomised as two or fewer versus three or more) related to lower RBANS Coding scores (information processing, $t(71)=3.576, p=.001$ ). There were no differences in assessment scores (or a range of demographic and clinical variables) between a group which completed $\geq 90 \%(\mathrm{n}=25)$ of the assessments and those who completed $<90 \%$ (n =62), with one exception: RBANS Immediate Story Memory $(t(65.236)=-3.439, p=.043)$. 


\section{Discussion}

This study was the first to employ such a broad battery of standardised neuropsychological assessments, selected purposefully to be sensitive to common features of VCI, to provide a profile of cognitive functioning in admissions to rehabilitation programmes. The profile is one of high degree and prevalence of impairment in overall cognitive functioning as well as widespread impairment across domains, including reasoning, information processing, attention, immediate memory/learning, delayed recall and recognition memory, naming less commonplace objects, visuospatial perception and construction, and executive functions including cognitive flexibility/set-shifting, inhibition, verbal fluency, and planning. Particular difficulties, in both magnitude and prevalence of difficulty, were evident in overall cognitive functioning; processing speed(especially under time pressure); focusing attention and sustaining concentration; learning verbal information, and; recalling newly learned

276 information even with cuing. Among executive functions, cognitive flexibility (switching

277 between tasks and thinking creatively), and planning presented particular difficulties.

The results support research suggesting increased overall susceptibility to cognitive impairment ${ }^{2}$, impaired processing speed and executive functioning ${ }^{11}$ and reduced immediate and delayed list recall and verbal fluency across time in dysvascular LLA ${ }^{10}$, and similar 
findings in PVD ${ }^{3}$. Importantly, this study evidences impairment across a much wider range of cognitive domains.

In economically developed countries, persons with dysvascular LLA predominate in

LLA rehabilitation programmes. Impairment observed in these individuals is likely linked to

with overall cognitive functioning with particularly high frequency of impairments of

processing speed, executive functioning, attention, and memory. Yet, LLA aetiology does not map reliably onto impairment status. The similarly poor performance of non-vascular LLA participants across the full range of assessments raises questions about cognitive functioning in this group. Previous research on found that people with traumatic LLA were no less concerned about their cognitive functioning than those with vascular LLA ${ }^{20}$, though how subjective concerns map onto and objective assessments of cognitive functioning is uncertain. Demographic or clinical factors, including distress, did not explain the lack of difference between aetiologies. One possible explanation is the presence of vascular risk factors; a third of the non-vascular group had cardiovascular comorbidities. Additional risk of traumatic amputation in dysvascularity has been reported previously ${ }^{33}$ (vascular insufficiency likely being a contributory factor).

Half of participants scored below the selected cut-off for cognitive impairment (MoCA <24), suggesting that comprehensive neuropsychological assessment may be appropriate for at least half of LLA rehabilitation programme admissions. Cut-off sensitivity and specificity ${ }^{32}$ suggest that approximately a quarter of participants could meet MCI criteria. A reliable and valid cognitive screen, sensitive to VCI, should be administered on admission to LLA rehabilitation, even to those with non-vascular LLA aetiology. Individuals' patterns of strengths and impairments varied with complexity which could not have been captured with categorical measures alone (e.g. screening pass/fail). More accurate and precise 
understandings of patients' relative or actual strengths and weaknesses are possible by

twinning cognitive screening as standard with comprehensive neuropsychological assessment as required. A non-exhaustive list of instances suggesting benefit in neuropsychological assessment includes: scoring below or near a cognitive screen cut off; notable discrepancies between scores in different domains on a cognitive screen; functional difficulties suggestive of cognitive difficulties; and self-reported or other-reported cognitive difficulties.

While there are clear resource implications for implementing neuropsychological assessment, potential benefits include earlier and better understanding of why difficulties may arise with particular tasks, functioning, or activities of daily living ${ }^{34,35}$, prosthesis use or mobility ${ }^{36-39}$, self-management and compliance with medical regimen ${ }^{40,41}$, or social integration and community participation ${ }^{39}$. Additionally, declines in cognitive functioning may have implications for sustaining achieved goals in the longer term. Prospective associations between cognitive functioning and rehabilitation outcomes suggest an influence on longer-term outcomes ${ }^{36,39}$. Timely assessment would improve potential for earlier intervention to mitigate these difficulties with concomitant benefits of reduced healthcare expenditure and resource use.

Research is required to examine whether lower premorbid cognitive functioning or intellectual ability confer additional amputation risk. While mean estimated premorbid intellectual ability did not differ from normative values, a greater proportion of this sample was in the borderline and extremely low ranges. Self-management of later-stage PVD carries a cognitive burden and requires motivation. Brief cognitive screening for at-risk persons could contribute to LLA prevention.

This study evidences impairment across attention, memory, and executive functions which could reasonably be considered particularly important for rehabilitation and outcomes. 
Intact cognitive functioning is likely to be important in learning to effectively and safely don, doff, transfer and ambulate with, and maintain prostheses, but LLA rehabilitation now extends beyond prosthetic provision and training ${ }^{9,42}$. Some people achieve functional independence and adjust well after LLA, yet others do not ${ }^{9}$. Reintegration into community living and social roles may depend somewhat on cognitive functions and their successful application. Some additional cognitive burdens for PwLLA include planning, activity organization, and memory for prosthetic procedures. Understanding precipitant factors of good and poor activity performance, participation, and overall adjustment to limb loss will assist in rehabilitation programme development and optimization. Cognitive rehabilitation has already yielded promising results in facilitating prosthesis use ${ }^{19}$ and its efficacy in improving other outcomes should be researched. Clinicians supporting emotional and psychological adjustment to amputation and prosthesis use should be mindful of the cognitive resources required and the potential for impaired cognitive functioning even in nondysvascular LLA. Lastly, how cognitive functioning impacts on the process of engagement in LLA rehabilitation itself and subsequent rehabilitation outcomes ${ }^{43}$ warrants examination.

\section{Study Limitations}

Differing completion rates for each of the neuropsychological assessments are a limitation of the present study. Assessments were undertaken during routine, busy rehabilitation programme schedules. Heterogeneous completion rates related to restrictions in participant scheduling and research availability, early discharge, declining to continue (often citing fatigue), and the time required for battery completion. Fractionation of assessment sessions due to fatigue and scheduling difficulties was previously reported in the only other study to report comparably comprehensive neuropsychological assessment in PwLLA ${ }^{11}$. 
The sample was slightly younger than all PwLLA attending rehabilitation at the

355

356

357

358

359

360

361

362

363 recruitment site. Additionally, those who agreed to participate may have represented a more engaged and motivated patient subset. Indeed, VCI has been associated with elevated apathy ${ }^{44}$. Thus, the profile presented may underestimate cognitive impairment present in the LLA rehabilitation population. Differing aetiology group sizes reflected the preponderance of dysvascular LLA common in industrialized countries, but make it difficult to draw firm conclusions about the relationship between cognitive functioning and aetiology. Multi-site recruitment with matched cases may facilitate recruitment of those less likely to participate and aetiological comparisons. Further research could also recruit an appropriate control group, for example persons with acquired physical impairment but without VCI risk.

Time of day (TOD) of testing may affect assessment performance across several neuropsychological variables of interest. Older age has been associated with lower performance in the afternoon compared to the morning, and vice versa for younger age ${ }^{45}$. While it was not possible to control for TOD effects within this study, this could be considered for future investigations.

Previous examinations of working memory in LLA have employed similar digit span measures to assess working memory, with similar null findings ${ }^{10,11,39}$. Digit forward and backward conditions incorporated in the WAIS-IV digit span test, measures of attention span and short term memory respectively ${ }^{46}$, potentially confounded assessment. Alternatives should be considered, e.g. digit ordered conditions alone, or $n$-back tasks ${ }^{47}$.

\section{Conclusions}

Difficulties with cognitive functioning in LLA are many, varied, and not confined to vascular LLA. A true representation of cognitive functioning is best obtained with a comprehensive 
379 in LLA could assist in supporting patients in rehabilitation and help them to optimise

380 rehabilitation outcomes and overall quality of life.

381

382

383

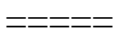

384

INCLUDE TABLE S1 AS ONLINE SUPPLEMENT

385 
References

387

1. Amputee Coalition of America. Amputation statistics by cause: Limb loss in the United States. Knoxville, TN: 2008.

2. Coffey L, O’Keeffe F, Gallagher P, Desmond D, Lombard-Vance R. Cognitive functioning in persons with lower limb amputations: a review. Disabil. Rehabil. 2012;34:1950-64.

3. Rafnsson SB, Deary IJ, Fowkes FGR. Peripheral arterial disease and cognitive function. Vasc. Med. 2009;14:51-61.

4. Laukka EJ, Starr JM, Deary IJ. Lower ankle-brachial index is related to worse cognitive performance in old age. Neuropsychology. 2014;28:281-9.

5. Guerchet M, Aboyans V, Nubukpo P, Lacroix P, Clément J-P, Preux P-M. Anklebrachial index as a marker of cognitive impairment and dementia in general population. A systematic review. Atherosclerosis. 2011;216:251-7.

6. Vasquez BP, Zakzanis KK. The neuropsychological profile of vascular cognitive impairment not demented: A meta-analysis. J. Neuropsychol. 2015;9:109-36.

7. Palta P, Schneider ALC, Biessels GJ, Touradji P, Hill-Briggs F. Magnitude of cognitive dysfunction in adults with type 2 diabetes: A meta-analysis of six cognitive domains and the most frequently reported neuropsychological tests within domains. J. Int. Neuropsychol. Soc. 2014;20:278-91.

8. Fiest KM, Jetté N, Roberts JI, Maxwell CJ, Smith EE, Black SE, et al. The prevalence and incidence of dementia: A systematic review and meta-analysis. Can. J. Neurol. Sci. 2016;43:S3-50.

9. Gallagher P, Desmond D, MacLachlan M. Psychoprosthetics. London: Springer- 
409

410

411

412

413

414

415

416

417

418

419

420

421

422

423

424

425

426

427

428

429

430

431

Verlag; 2008.

10. Williams RM, Turner AP, Green M, Norvell DC, Henderson AW, Hakimi KN, et al. Changes in cognitive function from presurgery to 4 months postsurgery in individuals undergoing dysvascular amputation. Arch. Phys. Med. Rehabil. 2014;95:663-9.

11. Phillips NA, Mate-Kole CC, Kirby RL. Neuropsychological function in peripheral vascular disease amputee patients. Arch. Phys. Med. Rehabil. 1993;74:1309-14.

12. Pinzur MS, Graham G, Osterman H. Psychologic testing in amputation rehabilitation. Clin. Orthop. Relat. Res. 1988;236-40.

13. Chiu C-C, Chen C-E, Wang T-G, Lin M-C, Lien Z-N. Influencing factors and ambulation outcome in patients with dual disabilities of hemiplegia and amputation. Arch. Phys. Med. Rehabil. 2000;81:14-7.

14. Fletcher DD, Andrews KL, Butters MA, Jacobsen SJ, Rowland CM, Hallett JW. Rehabilitation of the geriatric vascular amputee patient: A population-based study. Arch. Phys. Med. Rehabil. 2001;82:776-9.

15. Taylor S, Kalbaugh C, Blackhurst D, Hamontree S, Cull D, Messich H, et al. Preoperative clinical factors predict postoperative functional outcomes after major lower limb amputation: An analysis of 553 consecutive patients. J. Vasc. Surg. $2005 ; 42: 227-35$.

16. Couch NP, David JK, Tilney NL, Crane C. Natural history of the leg amputee. Am. J. Surg. 1977;133:469-73.

17. Wang P, Kaplan J, Rogers E. Memory functioning in hemiplegics: A neuropsychological analysis of the Wechsler Memory scale. Arch. Phys. Med. Rehabil. 1975;56:517-21. 
18. Willrich A, Pinzur M, McNeil M, Juknelis D, Lavery L. Health related quality of life, cognitive function, and depression in diabetic patients with foot ulcer or amputation. A preliminary study. Foot Ankle Int. 2005;26:128-34.

19. O'Neill BF, Moran K, Gillespie A. Scaffolding rehabilitation behaviour using a voicemediated assistive technology for cognition. Neuropsychol. Rehabil. 2010;20:509-27.

20. Morgan SJ, Kelly VE, Amtmann D, Salem R, Hafner BJ. Self-reported cognitive concerns in people with lower limb loss. Arch. Phys. Med. Rehabil. 2016;97:912-8.

21. Roebuck-Spencer TM, Glen T, Puente AE, Denney RL, Ruff RM, Hostetter G, et al. Cognitive screening tests versus comprehensive neuropsychological test batteries: A National Academy of Neuropsychology education paper. Arch. Clin. Neuropsychol. $2017 ; 32: 491-8$.

22. Zigmond AS, Snaith RP. The hospital anxiety and depression scale. Acta Psychiatr. Scand. 1983;67:361-70.

23. Crawford JR, Henry JD, Crombie C, Taylor EP. Normative data for the HADS from a large non-clinical sample. Br. J. Clin. Psychol. 2001;40:429-34.

24. O'Keeffe F, Ganesan V, King J, Murphy T. Quality-of-life and psychosocial outcome following childhood arterial ischaemic stroke. Brain Inj. 2012;26:1072-83.

25. Strauss E, Sherman EMS, Spreen O. A compendium of neuropsychological tests: Administration, norms, and commentary. 3rd ed. Oxford: Oxford University Press; 2006.

26. Libon DJ, Xie SX, Eppig J, Wicas G, Lamar M, Lippa C, et al. The heterogeneity of mild cognitive impairment: a neuropsychological analysis. J. Int. Neuropsychol. Soc. 2010;16:84-93. 
27. Nordlund A, Rolstad S, Klang O, Lind K, Hansen S, Wallin A. Cognitive profiles of mild cognitive impairment with and without vascular disease. Neuropsychology. $2007 ; 21: 706-12$.

28. Göthlin M, Eckerström M, Rolstad S, Wallin A, Nordlund A. Prognostic Accuracy of Mild Cognitive Impairment Subtypes at Different Cut-Off Levels. Dement. Geriatr. Cogn. Disord. 2017;43:330-41.

29. Grace J, Malloy PF. Frontal Systems Behavior Scale (FrSBe): Professional Manual. Lutz, FL.: Psychological Assessment Resources; 2001.

30. Aickin M, Gensler H. Adjusting for multiple testing when reporting research results: The Bonferroni vs Holm methods. Am. J. Public Health. 1996;86:726-8.

31. Gaetano J. Holm-Bonferroni sequential correction: An EXCEL calculator (1.1) [Microsoft Excel workbook] [Internet]. 2013;Available from: www.researchgate.net/publication/236969037_HolmBonferroni_Sequential_Correction_An_EXCEL_Calculator

32. McLennan SN, Mathias JL, Brennan LC, Stewart S. Validity of the Montreal Cognitive Assessment (MoCA) as a screening test for mild cognitive impairment (MCI) in a cardiovascular population. J. Geriatr. Psychiatry Neurol. 2011;24:33-8.

33. Fosse S, Hartemann-Huertier A, Jacqueminet S, Ha Van G, Grimaldi A, FagotCampagna A. Incidence and characteristics of lower limb amputations in people with diabetes. Diabet. Med. 2009;26:391-6.

34. Royall DR, Lauterbach EC, Kaufer D, Malloy P, Ph D, Coburn KL, et al. The cognitive correlates of functional status: A review from the Committee on Research of the American Neuropsychiatric Association. J. Neuropsychiatry Clin. Neurosci. 2007;19:249-65. 
35. Schoppen T, Boonstra A, Groothoff JW, De Vries J, Göeken LN, Eisma WH. Physical, mental, and social predictors of functional outcome in unilateral lower-limb amputees. Arch. Phys. Med. Rehabil. 2003;84:803-11.

36. O’Neill BF, Evans JJ. Memory and executive function predict mobility rehabilitation outcome after lower-limb amputation. Disabil. Rehabil. 2009;31:1083-91.

37. Bilodeau S, Hébert R, Desrosiers J. Lower limb prosthesis utilisation by elderly amputees. Prosthet. Orthot. Int. 2000;24:126-32.

38. Larner S, van Ross E, Hale C. Do psychological measures predict the ability of lower limb amputees to learn to use a prosthesis? Clin. Rehabil. 2003;17:493-8.

39. Williams RM, Turner AP, Green M, Norvell DC, Henderson AW, Hakimi KN, et al. Relationship between cognition and functional outcomes after dysvascular lower extremity amputation. Am. J. Phys. Med. Rehabil. 2015;94:707-17.

40. Feil DG, Zhu CW, Sultzer DL. The relationship between cognitive impairment and diabetes self-management in a population-based community sample of older adults with Type 2 diabetes. J. Behav. Med. 2012;35:190-9.

41. Coetzee N, Andrewes D, Khan F, Hale T, Jenkins L, Lincoln N, et al. Predicting compliance with treatment following stroke: A new model of adherence following rehabilitation. Brain Impair. 2008;122:122-39.

42. Desmond DM, Coffey L, Gallagher P, MacLachlan M, Wegener ST, O'Keeffe F. Limb Amputation. Oxford: Oxford University Press; 2012.

43. Kortte KB, Falk LD, Castillo RC, Johnson-Greene D, Wegener ST. The Hopkins Rehabilitation Engagement Rating Scale: development and psychometric properties. Arch. Phys. Med. Rehabil. 2007;88:877-84. 
502

503

504

505

506

507

508

509

510

511

512

\section{ACCEPTED MANUSCRIPT}

44. Chin J, Seo SW, Kim SH, Park A, Ahn H-J, Lee BH, et al. Neurobehavioral dysfunction in patients with subcortical vascular mild cognitive impairment and subcortical vascular dementia. Clin. Neuropsychol. 2012;26:224-8.

45. Schmidt C, Collette F, Cajochen C, Peigneux P. A time to think: Circadian rhythms in human cognition. Cogn. Neuropsychol. 2007;24:755-89.

46. St Clair-Thompson HL. Backwards digit recall: A measure of short-term memory or working memory? Eur. J. Cogn. Psychol. 2010;22:286-96.

47. Lezak MD, Howieson DB, Digler ED, Tranel D. Neuropsychological assessment. 5th ed. Oxford: Oxford University Press; 2012. 
Table 1

Demographic and Clinical Characteristics of the Sample

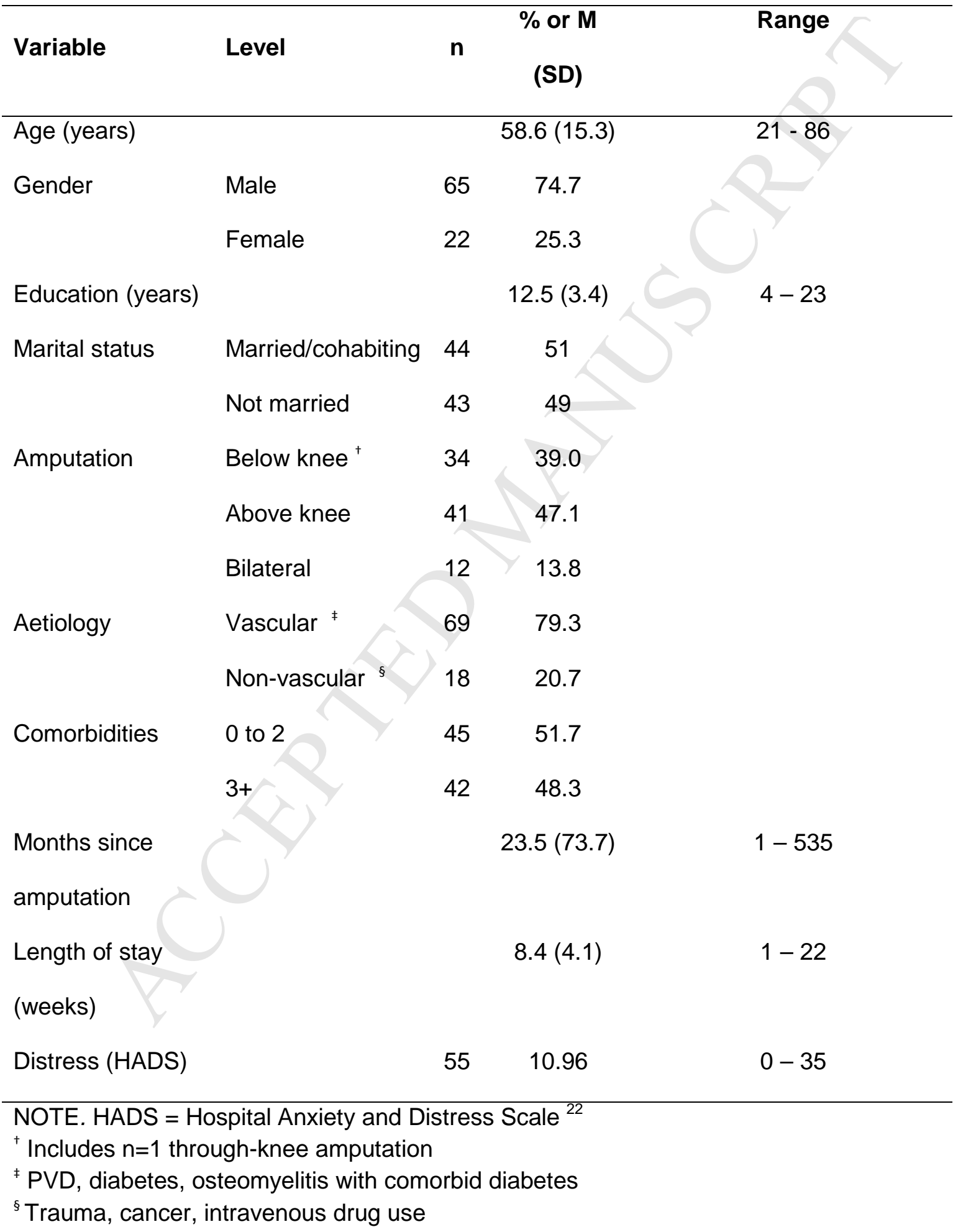


Table 2

Neuropsychological Assessment Scores

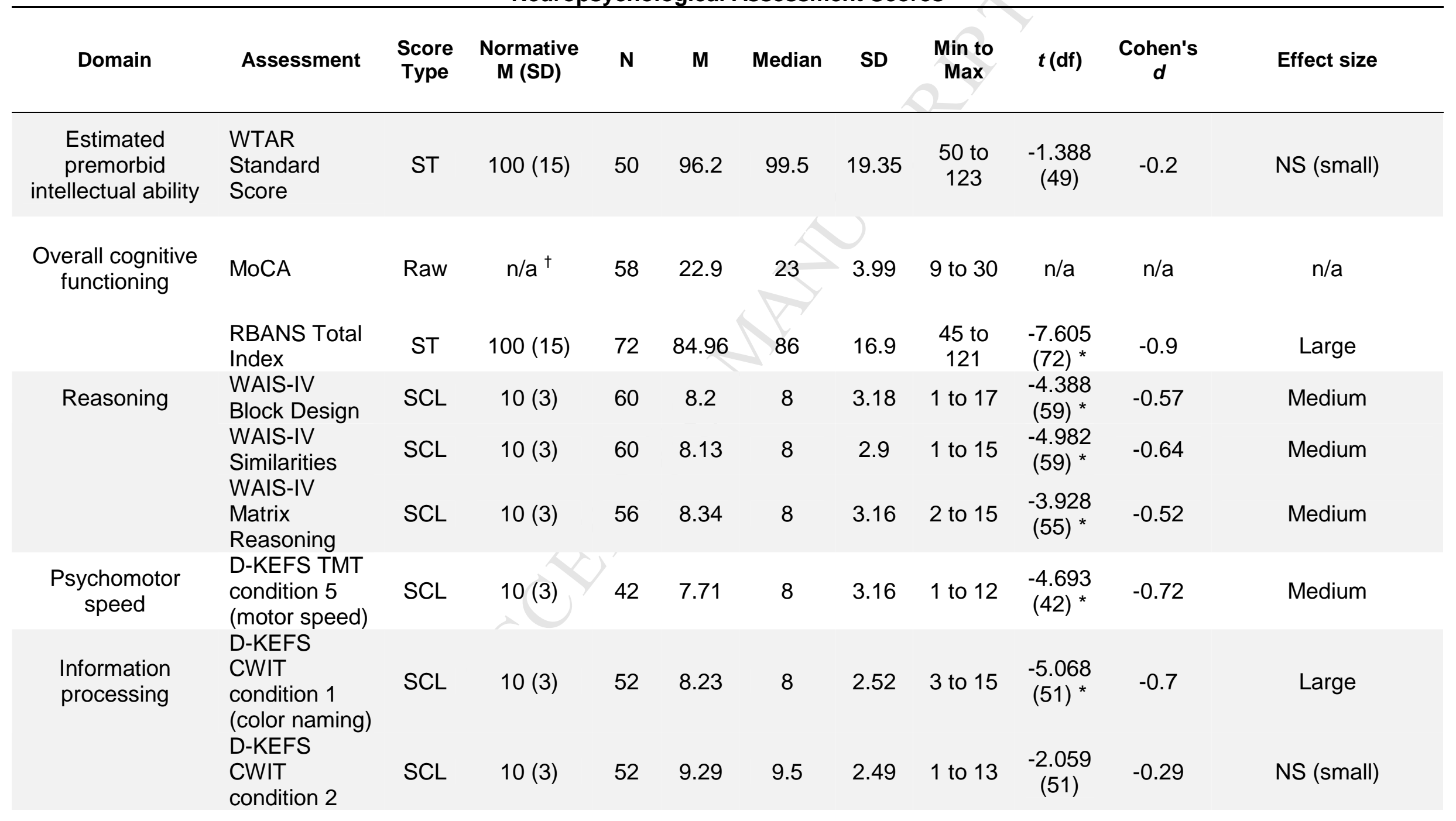




\begin{tabular}{|c|c|c|c|c|c|c|c|c|c|c|c|}
\hline & (word reading) & & & & & & & & & & \\
\hline & $\begin{array}{l}\text { RBANS } \\
\text { Coding }\end{array}$ & Z & $0(1)$ & 73 & -1.77 & -1.65 & 1.41 & $\begin{array}{l}-5.08 \text { to } \\
+1.54\end{array}$ & $\begin{array}{c}- \\
10.699 \\
(72)^{*}\end{array}$ & -1.25 & Large \\
\hline & $\begin{array}{l}\text { WAIS-IV } \\
\text { Symbol } \\
\text { Search }\end{array}$ & SCL & $10(3)$ & 60 & 6.98 & 6.5 & 2.94 & 1 to 18 & $\begin{array}{l}-7.940 \\
(59)^{*}\end{array}$ & -1.03 & Large \\
\hline \multirow[t]{6}{*}{ Attention } & $\begin{array}{l}\text { RBANS Digit } \\
\text { Span }\end{array}$ & Z & $0(1)$ & 76 & 0.07 & 0.18 & 1.12 & $\begin{array}{c}-2.47 \text { to } \\
+2.29\end{array}$ & $\begin{array}{c}1.014 \\
(75)\end{array}$ & 0.12 & NS (negligible) \\
\hline & $\begin{array}{l}\text { D-KEFS TMT } \\
\text { condition } 1 \\
\text { (visual } \\
\text { scanning) }\end{array}$ & SCL & $10(3)$ & 52 & 7.85 & 9 & 3.1 & 1 to 13 & $\begin{array}{l}-5.007 \\
(51)^{*}\end{array}$ & -0.69 & Medium \\
\hline & $\begin{array}{l}\text { D-KEFS TMT } \\
\text { condition } 2 \\
\text { (number } \\
\text { sequencing) }\end{array}$ & SCL & $10(3)$ & 54 & 7.17 & 8 & 3.88 & 1 to 14 & $\begin{array}{l}-5.367 \\
(53)^{*}\end{array}$ & -0.73 & Medium \\
\hline & $\begin{array}{l}\text { D-KEFS TMT } \\
\text { condition } 3 \\
\text { (letter } \\
\text { sequencing) }\end{array}$ & SCL & $10(3)$ & 53 & 6.81 & 8 & 3.93 & 1 to 14 & $\begin{array}{l}-5.911 \\
(52) *\end{array}$ & -0.81 & Large \\
\hline & $\begin{array}{l}\text { TEA } \\
\text { Telephone } \\
\text { Search } \\
\text { TEA }\end{array}$ & SCL & $10(3)$ & 32 & 5.84 & 6 & 2.96 & 1 to 13 & $\begin{array}{c}-7.934 \\
(31)^{*}\end{array}$ & -1.45 & Large \\
\hline & $\begin{array}{l}\text { Telephone } \\
\text { Search With } \\
\text { Counting }\end{array}$ & SCL & $10(3)$ & 32 & 9.13 & 8.5 & 4.14 & 1 to 19 & $\begin{array}{c}-1.195 \\
(31)\end{array}$ & -0.22 & NS (small) \\
\hline \multirow[t]{2}{*}{ Memory } & $\begin{array}{l}\text { RBANS List } \\
\text { Learning }\end{array}$ & Z & $0(1)$ & 76 & -1.03 & -0.96 & 1.2 & $\begin{array}{c}-3.88 \text { to } \\
+1.38\end{array}$ & $\begin{array}{l}-6.940 \\
(75)^{*}\end{array}$ & -0.8 & Large \\
\hline & $\begin{array}{l}\text { CVLT-II SF } \\
\text { Free Recall T- } \\
\text { Score (list) }\end{array}$ & $\mathrm{T}$ & $50(10)$ & 56 & 44.95 & 47 & 11.97 & $\begin{array}{c}18 \text { to } \\
66\end{array}$ & $\begin{array}{c}-3.161 \\
(55)^{*}\end{array}$ & -0.42 & Medium \\
\hline
\end{tabular}




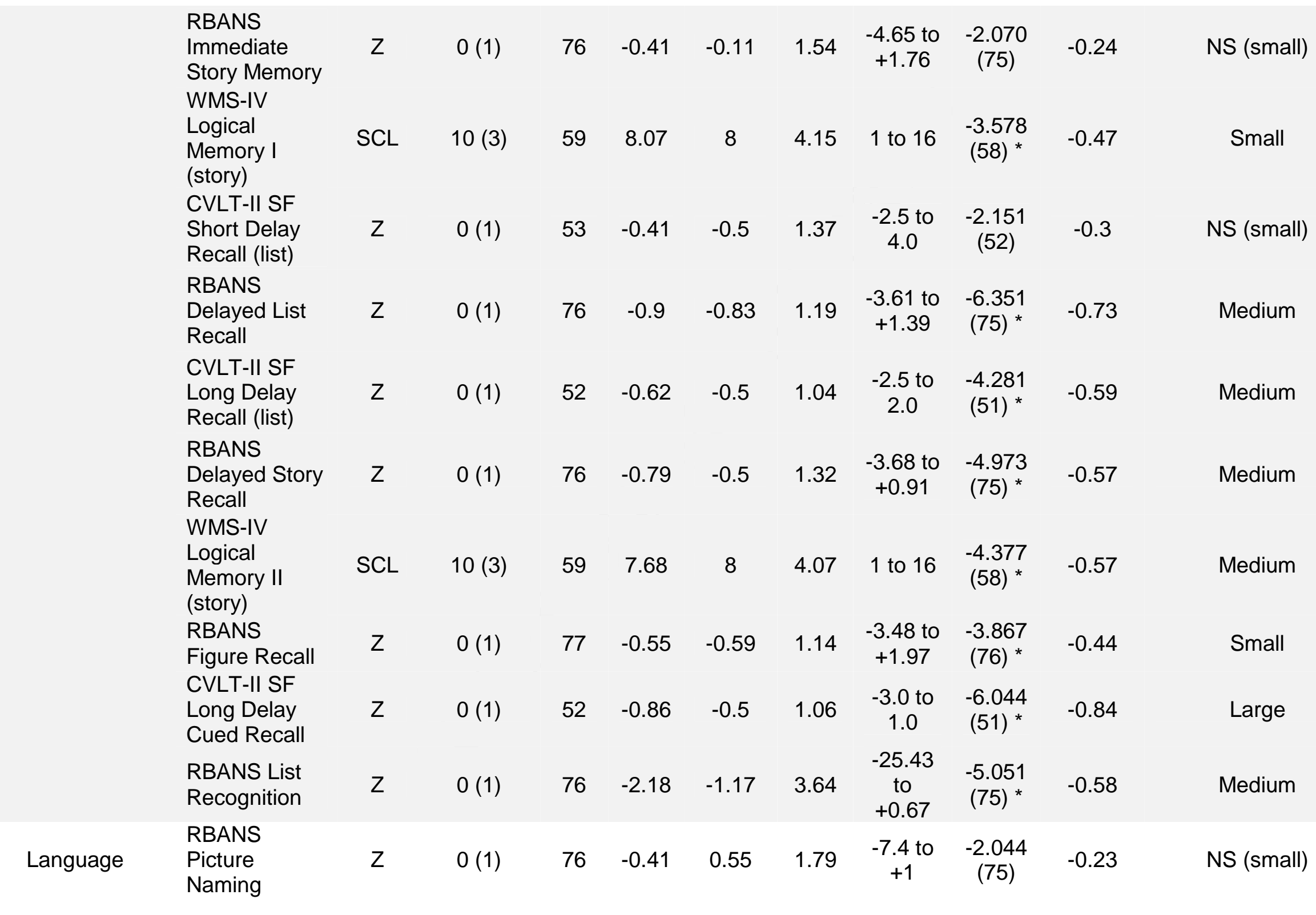




\begin{tabular}{|c|c|c|c|c|c|c|c|c|c|c|c|}
\hline & $\begin{array}{l}\text { GNT raw } \\
\text { score }\end{array}$ & Raw & $\mathrm{n} / \mathrm{a}^{\dagger}$ & 39 & 16.59 & 18 & 6.44 & 3 to 27 & $\mathrm{n} / \mathrm{a}$ & & \\
\hline \multirow[t]{3}{*}{$\begin{array}{l}\text { Visuospatial } \\
\text { cognition }\end{array}$} & $\begin{array}{l}\text { RBANS } \\
\text { Figure Copy }\end{array}$ & Z & $0(1)$ & 77 & -1.11 & -0.85 & 2.05 & $\begin{array}{l}-8 \text { to } \\
+1.29\end{array}$ & $\begin{array}{l}-4.745 \\
(76)^{*}\end{array}$ & -0.54 & Medium \\
\hline & $\begin{array}{l}\text { RBANS Line } \\
\text { Orientation }\end{array}$ & Z & $0(1)$ & 77 & -0.28 & 0.12 & 1.68 & $\begin{array}{l}-5.5 \text { to } \\
+4.62\end{array}$ & $\begin{array}{c}-1.458 \\
(76)\end{array}$ & -0.17 & Negligible \\
\hline & $\begin{array}{l}\text { VOSP } \\
\text { Position } \\
\text { Discrimination } \\
\text { raw }\end{array}$ & Raw & $\mathrm{n} / \mathrm{a}^{\dagger}$ & 43 & 18.98 & 20 & 1.61 & $\begin{array}{l}12 \text { to } \\
20\end{array}$ & $\mathrm{n} / \mathrm{a}$ & $\mathrm{n} / \mathrm{a}$ & $\mathrm{n} / \mathrm{a}$ \\
\hline \multirow[t]{8}{*}{$\begin{array}{l}\text { Executive } \\
\text { functions }\end{array}$} & $\begin{array}{l}\text { WAIS-IV Digit } \\
\text { Span } \\
\text { D-KEFS }\end{array}$ & SCL & $10(3)$ & 62 & 9.52 & 3.2 & 10 & 2 to 17 & $\begin{array}{c}-1.192 \\
(61)\end{array}$ & -0.15 & Negligible \\
\hline & $\begin{array}{l}\text { CWIT } \\
\text { condition } 3 \\
\text { (colour-word } \\
\text { switching) } \\
\text { D-KEFS TMT }\end{array}$ & SCL & $10(3)$ & 50 & 7 & 8 & 3.95 & 1 to 13 & $\begin{array}{l}-5.365 \\
(49)^{*}\end{array}$ & -0.76 & Medium \\
\hline & $\begin{array}{l}\text { condition } 4 \\
\text { (number-letter } \\
\text { switching) }\end{array}$ & $\mathrm{SCL}$ & $10(3)$ & 53 & 5.81 & 6 & 3.99 & 1 to 13 & $\begin{array}{l}-7.651 \\
(52)^{*}\end{array}$ & -1.05 & Large \\
\hline & $\begin{array}{l}\text { RBANS } \\
\text { Semantic } \\
\text { Fluency } \\
\text { D-KEFS VFT }\end{array}$ & Z & $0(1)$ & 76 & -0.91 & -1 & 1.22 & -3 to +2 & $\begin{array}{l}-6.309 \\
(75)^{*}\end{array}$ & -0.72 & Medium \\
\hline & $\begin{array}{l}\text { condition } 1 \\
\text { (category } \\
\text { fluency) }\end{array}$ & $\mathrm{SCL}$ & $10(3)$ & 57 & 8.42 & 8 & 3.74 & 3 to 17 & $\begin{array}{l}-3.186 \\
(56)^{*}\end{array}$ & -0.42 & Small \\
\hline & $\begin{array}{l}\text { D-KEFS VFT } \\
\text { condition } 2 \\
\text { (letter fluency) }\end{array}$ & SCL & $10(3)$ & 57 & 8.12 & 8 & 3.73 & 2 to 19 & $\begin{array}{l}-3.802 \\
(56)^{*}\end{array}$ & -0.5 & Medium \\
\hline & $\begin{array}{l}\text { BADS Zoo } \\
\text { Map }\end{array}$ & Raw & $\mathrm{n} / \mathrm{a}^{\dagger}$ & 41 & $n / a$ & 2 & $\mathrm{n} / \mathrm{a}$ & 1 to 6 & $n / a$ & $n / a$ & $n / a$ \\
\hline & FrSBe self & $\mathrm{T}$ & $50(10)$ & 35 & 59.8 & 53 & 16.66 & 33 to & 3.481 & 0.59 & Medium \\
\hline
\end{tabular}


NOTE. BADS = Behavioural Assessment of the Dysexecutive Syndrome ${ }^{38}$; CVLT-II SF = California Verbal Learning Test - II Short Form ${ }^{39}$; D-KEFS = Delis-Kaplan Executive Function System (CWIT = Color-Word Interference Test; TMT = Trail Making Test; VFT = Verbal Fluency Test) ${ }^{40}$; FrSBe $=$ Frontal Systems Behavior Scale ${ }^{21}$; GNT = Graded Naming Test ${ }^{41}$; MoCA = Montreal Cognitive Assessment ${ }^{42}$; RBANS $=$ Repeatable Battery for the Assessment of Neuropsychological Status ${ }^{43}$; TEA $=$ Test of Everyday Attention ${ }^{44}$; VOSP $=$ Visual Object and Space Perception Battery ${ }^{45}$; WAIS-IV $=$ Wechsler Adult Intelligence Scales - IV ${ }^{46}$; WMS-IV = Wechsler Memory Scales - IV ${ }^{47}$; WTAR $=$ Wechsler Test of Adult Reading ${ }^{48}$

* significant ( $p \leq .003$ ) after the Holm method of correction for multiple comparisons was employed

${ }^{\dagger}$ Raw scores: MoCA and GNT each have a possible raw scores ranging from 0 to 30 . VOSP possible scores range from 0-20 (pass $\geq 19$, pass borderline $=18$, fail/impaired $\leq 17 / 20$ ). BADS zoo map possible scores range from 1 to 7 (pro-rated ordinal scale). 
Table 3

Neuropsychological Assessments: Proportions of Scores in the Borderline or Impaired Ranges

\begin{tabular}{|c|c|c|c|c|c|c|c|c|c|c|c|c|}
\hline Domain & Assessment & $\mathbf{N}$ & $\begin{array}{c}\% \\
\text { borderline }\end{array}$ & $\begin{array}{c}\% \\
\text { impaired }\end{array}$ & $\begin{array}{c}\% \\
\text { impaired } \\
\text { or border. }\end{array}$ & $p$ & $\begin{array}{c}x^{2} \\
(d f=2)\end{array}$ & $\begin{array}{c}\text { Aetiolo } \\
\text { gy }\end{array}$ & $\mathbf{N}$ & $\%$ impaired & $\begin{array}{c}\% \\
\text { borderline }\end{array}$ & $\begin{array}{l}\% \text { impaired } \\
\text { or border. }\end{array}$ \\
\hline \multirow{6}{*}{$\begin{array}{c}\text { Estimated } \\
\text { premorbid } \\
\text { intellectual } \\
\text { ability } \\
\text { Overall } \\
\text { cognitive } \\
\text { functioning }\end{array}$} & $\begin{array}{c}\text { WTAR } \\
\text { Standard }\end{array}$ & 50 & 12 & 10 & 22 & $.001^{*}$ & 22.11 & VAS & 38 & 10.5 & 13.2 & 23.7 \\
\hline & Score & & & & & & & NV & 12 & 8.3 & 8.3 & 16.7 \\
\hline & MoCA & 58 & $\mathrm{n} / \mathrm{a}$ & $\mathrm{n} / \mathrm{a}$ & $52.6^{\dagger}$ & $\mathrm{n} / \mathrm{a}$ & $\mathrm{n} / \mathrm{a}$ & VAS & 49 & $\mathrm{n} / \mathrm{a}$ & $\mathrm{n} / \mathrm{a}$ & 61.2 \\
\hline & & & & & & & & NV & 9 & $\mathrm{n} / \mathrm{a}$ & $\mathrm{n} / \mathrm{a}$ & 11.1 \\
\hline & RBANS Total & 72 & 12.3 & 21.9 & 34.2 & $<.001^{*}$ & 158.47 & VAS & 58 & 24.1 & 13.8 & 37.9 \\
\hline & Index & & & & & & & NV & 15 & 13.3 & 6.7 & 20.0 \\
\hline \multirow[t]{6}{*}{ Reasoning } & $\begin{array}{c}\text { WAIS-IV } \\
\text { Block Design }\end{array}$ & 60 & 13.3 & 5 & 18.3 & 0.017 & 11.86 & VAS & 48 & 4.2 & 16.7 & 20.8 \\
\hline & & & & & & & & NV & 12 & 8.3 & 0 & 8.3 \\
\hline & $\begin{array}{l}\text { WAIS-IV } \\
\text { Similarities }\end{array}$ & 60 & 10 & 6.7 & 6.7 & 0.021 & 10.14 & VAS & 48 & 8.3 & 6.3 & 14.6 \\
\hline & WAIS-IV & & & & & & & NV & 12 & 0 & 25 & 25 \\
\hline & $\begin{array}{c}\text { Matrix } \\
\text { Reasoning }\end{array}$ & 56 & 17.9 & & 21.4 & $.003^{*}$ & 20.46 & VAS & 44 & 4.5 & 18.2 & 22.7 \\
\hline & & & & & & & & NV & 12 & 0 & 16.7 & 16.7 \\
\hline \multirow[t]{2}{*}{$\begin{array}{l}\text { Psychomot } \\
\text { or speed }\end{array}$} & $\begin{array}{l}\text { D-KEFS TMT } \\
\text { condition } 5 \\
\text { (motor speed) }\end{array}$ & 42 & 7.1 & 11.9 & 19 & $.001^{*}$ & 21.64 & VAS & 32 & 12.5 & 6.3 & 18.8 \\
\hline & & & & & & & & NV & 10 & 10 & 10 & 20 \\
\hline \multirow[t]{2}{*}{$\begin{array}{l}\text { Information } \\
\text { processing }\end{array}$} & $\begin{array}{c}\text { D-KEFS CWIT } \\
\text { condition } 1 \\
\text { (color naming) }\end{array}$ & 52 & 7.7 & 3.8 & 11.5 & 0.438 & 1.76 & VAS & 40 & 2.5 & 10 & 12.5 \\
\hline & D-KEFS CWIT & 52 & 1.9 & 1.9 & 3.8 & 0.676 & 1.04 & $\begin{array}{l}\text { NV } \\
\text { VAS }\end{array}$ & $\begin{array}{l}12 \\
40\end{array}$ & $\begin{array}{l}8.3 \\
2.5\end{array}$ & $\begin{array}{c}0 \\
2.5\end{array}$ & $\begin{array}{c}8.3 \\
5\end{array}$ \\
\hline
\end{tabular}




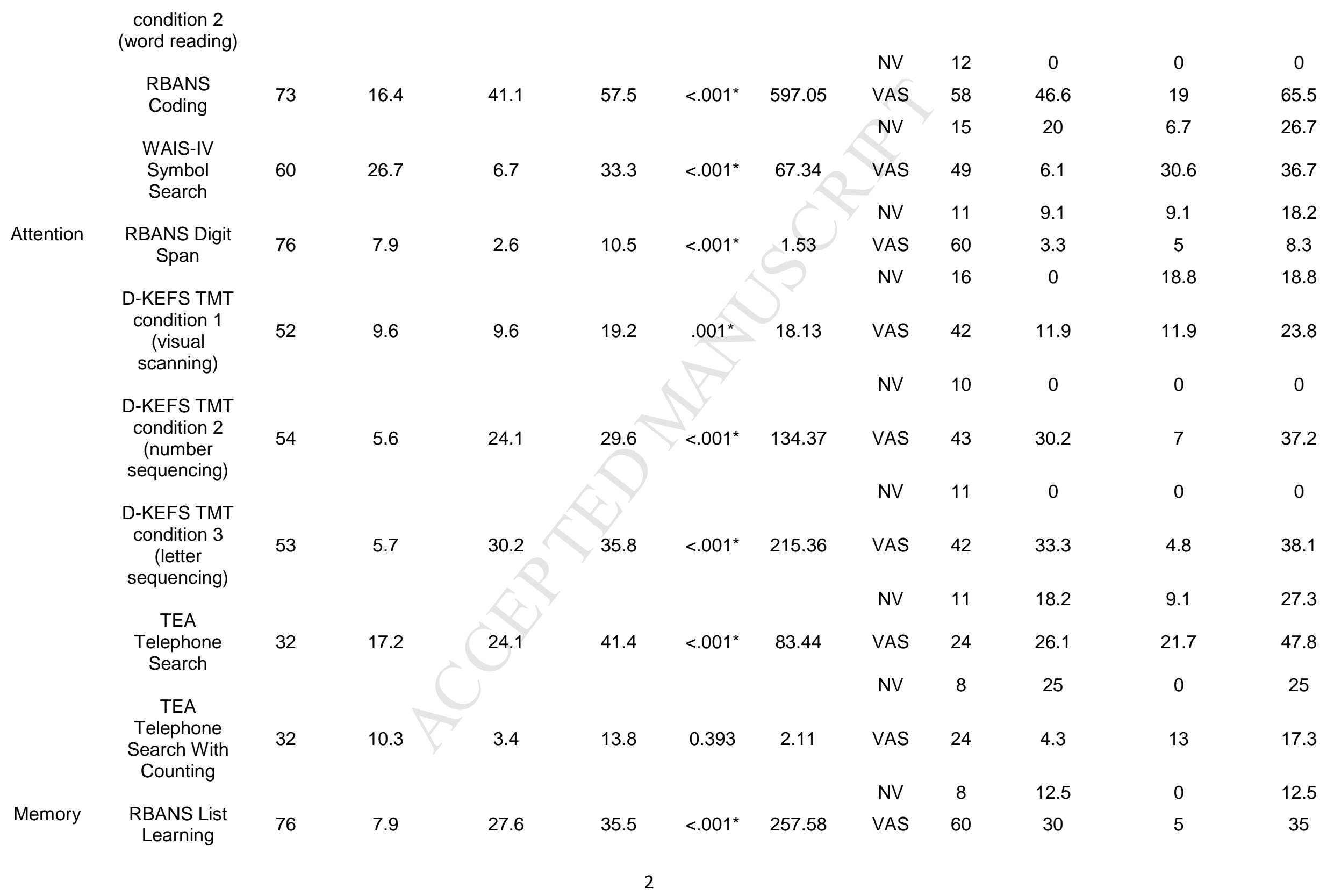




\begin{tabular}{|c|c|c|c|c|c|c|c|c|c|c|c|}
\hline CVLT-II SF & & & & & & & NV & 16 & 18.8 & 18.8 & 37.5 \\
\hline $\begin{array}{c}\text { Free Recall T- } \\
\text { Score (list) }\end{array}$ & 56 & 7.1 & 14.3 & 21.4 & $<.001^{*}$ & 44.03 & VAS & 44 & 15.9 & 9.1 & 25 \\
\hline RBANS & & & & & & & NV & 12 & 8.3 & 0 & 8.3 \\
\hline $\begin{array}{l}\text { Immediate } \\
\text { Story Memory }\end{array}$ & 76 & 6.9 & 16.1 & 23 & $<.001^{*}$ & 106.79 & VAS & 60 & 23.3 & 5 & 28.3 \\
\hline WMS-IV & & & & & & & NV & 16 & 0 & 18.8 & 18.8 \\
\hline $\begin{array}{l}\text { Logical } \\
\text { Memory I } \\
\text { (story) }\end{array}$ & 59 & 16.9 & 16.9 & 33.9 & $<.001^{*}$ & 87.36 & VAS & 48 & 16.7 & 16.7 & 33.3 \\
\hline CVLT-II SF & & & & & & & NV & 11 & 18.2 & 18.2 & 36.4 \\
\hline $\begin{array}{l}\text { Short Delay } \\
\text { Recall (list) }\end{array}$ & 53 & 11.3 & 15.1 & 26.4 & $<.001^{*}$ & 51.82 & VAS & 42 & 16.7 & 11.9 & 28.6 \\
\hline RBANS & & & & & & & $N V$ & 11 & 9.1 & 9.1 & 18.2 \\
\hline $\begin{array}{l}\text { Delayed List } \\
\text { Recall }\end{array}$ & 76 & 17.1 & 14.5 & 31.6 & $<.001^{*}$ & 86.34 & VAS & 60 & 15 & 18.3 & 33.3 \\
\hline CVLT-II SF & & & & & & & NV & 16 & 12.5 & 12.5 & 25 \\
\hline $\begin{array}{l}\text { Long Delay } \\
\text { Recall (list) }\end{array}$ & 52 & 7.7 & 19.2 & 26.9 & $<.001^{*}$ & 80.17 & VAS & 42 & 19 & 7.1 & 26.2 \\
\hline RBANS & & & & & & & NV & 10 & 20 & 10 & 30 \\
\hline $\begin{array}{l}\text { Delayed Story } \\
\text { Recall }\end{array}$ & 76 & 2.6 & 21.1 & 23.7 & $<.001^{*}$ & 141.07 & VAS & 60 & 25 & 3.3 & 28.3 \\
\hline WMS-IV & & & & & & & $N V$ & 16 & 6.3 & 0 & 6.3 \\
\hline $\begin{array}{l}\text { Logical } \\
\text { Memory II } \\
\text { (story) }\end{array}$ & 59 & 5.1 & 28.8 & 33.9 & $<.001^{*}$ & 216.69 & VAS & 48 & 29.2 & 2.1 & 31.3 \\
\hline & & & & & & & $N V$ & 11 & 27.3 & 18.2 & 45.5 \\
\hline $\begin{array}{c}\text { RBANS } \\
\text { Figure Recall }\end{array}$ & 77 & 13 & 9.1 & 22.1 & $<.001^{*}$ & 31.07 & VAS & 62 & 8.1 & 16.1 & 24.2 \\
\hline CVLT-II SF & 52 & 11.5 & 25 & 36.5 & $<.001^{*}$ & 146.87 & $\begin{array}{l}\text { NV } \\
\text { VAS }\end{array}$ & $\begin{array}{l}15 \\
42\end{array}$ & $\begin{array}{l}13.3 \\
28.6\end{array}$ & $\begin{array}{c}0 \\
11.9\end{array}$ & $\begin{array}{l}13.3 \\
40.5\end{array}$ \\
\hline
\end{tabular}




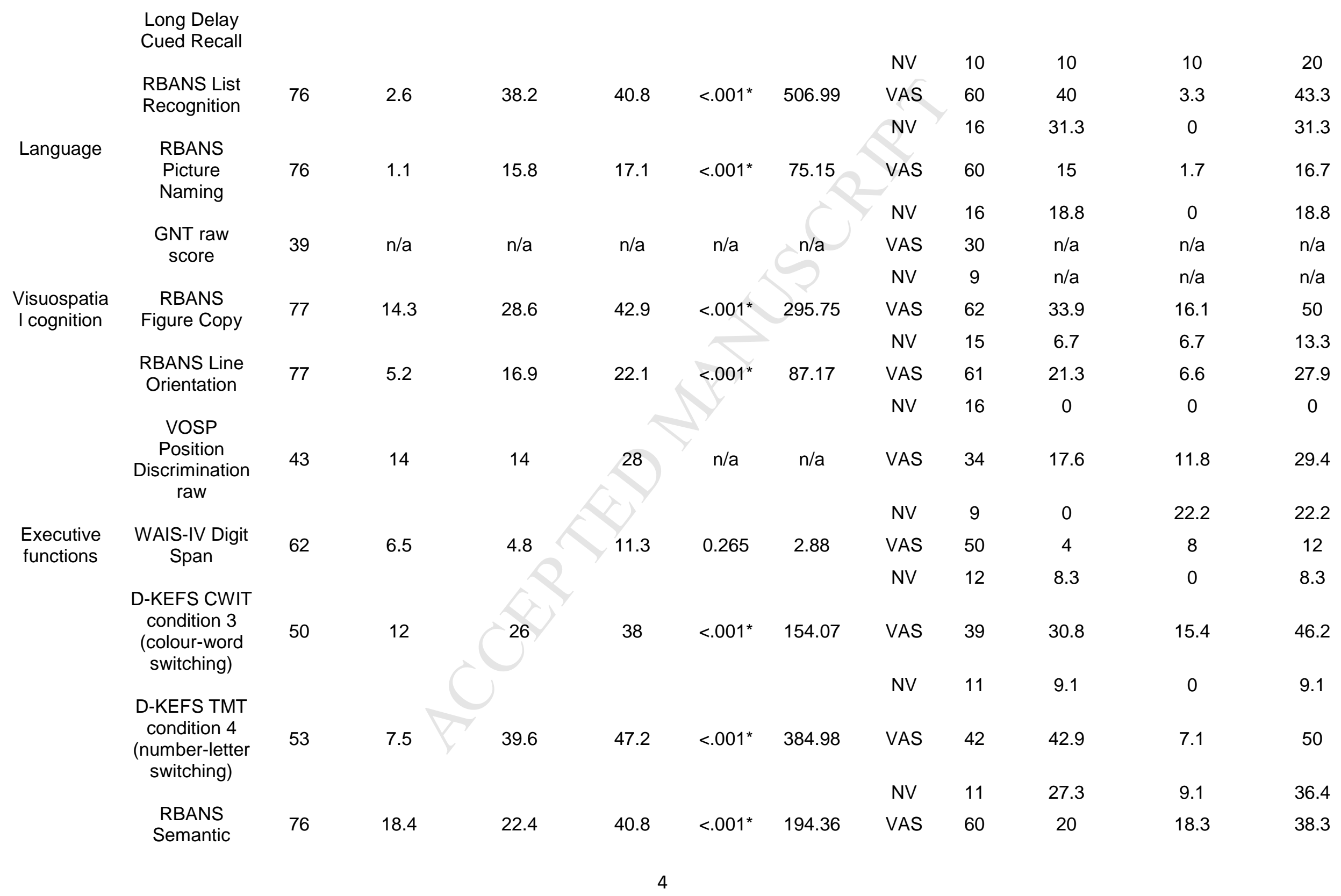




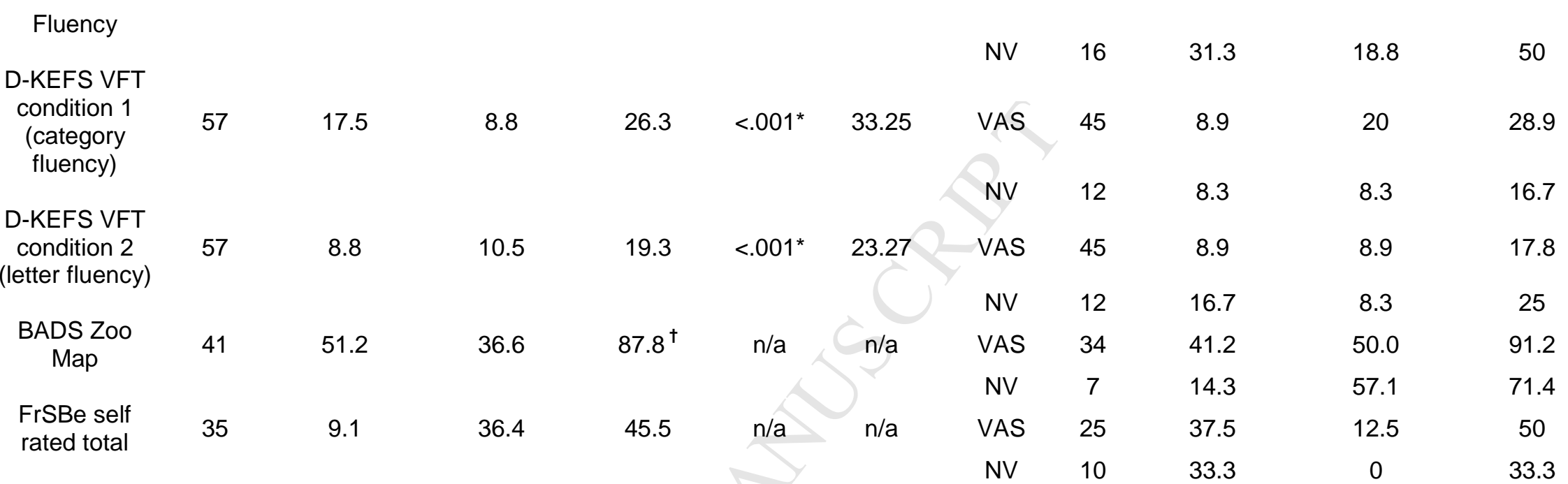

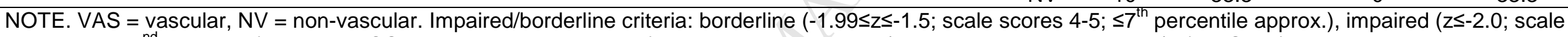
scores $1-3 ; \leq 2^{\text {nd }}$ percentile), except; VOSP Position Discrimination (borderline: raw score 18/20; impaired: raw score $\leq 17 / 20$ ), FrSBe (borderline: 60 $\leq \mathrm{T} \leq 64$; impaired: $T \geq 65$ ). For the WTAR, the score terminology is 'borderline' or 'extremely low'.

* significant $(\mathrm{p} \leq .003)$ after the Holm method of correction for multiple comparisons was employed

† \% scoring 23 or less for the MoCA brief cognitive screen; \% in two lowest BADS categories, 'borderline' and 'impaired', of seven-point ordinal classification). 
Cognitive Functioning: Comparison of Vascular (VAS) and Non-Vascular (NV) Aetiology Groups

\begin{tabular}{|c|c|c|c|c|c|c|c|c|c|}
\hline Domain & Assessment & $\begin{array}{l}\text { Score } \\
\text { Type }\end{array}$ & $\begin{array}{c}\text { Normative M } \\
\text { (SD) }\end{array}$ & Aetiology & $\mathbf{N}$ & M & Median & SD & Min to Max \\
\hline \multirow{2}{*}{$\begin{array}{c}\text { Estimated } \\
\text { premorbid } \\
\text { intellectual } \\
\text { ability }\end{array}$} & \multirow{2}{*}{$\begin{array}{l}\text { WTAR Standard } \\
\text { Score }\end{array}$} & ST & $100(15)$ & VAS & 38 & 95.71 & 99.5 & 20.56 & 50 to 123 \\
\hline & & & & NV & 12 & 97.75 & 100 & 15.61 & 64 to 120 \\
\hline \multirow{4}{*}{$\begin{array}{l}\text { Overall cognitive } \\
\text { functioning }\end{array}$} & \multirow[t]{2}{*}{ MoCA } & Raw & $\mathrm{n} / \mathrm{a} \dagger$ & VAS & 49 & 22.41 & 23 & 3.99 & 9 to 30 \\
\hline & & & & NV & 9 & 25.56 & 26 & 2.96 & 19 to 29 \\
\hline & \multirow[t]{2}{*}{ RBANS Total Index } & ST & $100(15)$ & VAS & 58 & 83.5 & 84.5 & 17.43 & 45 to 121 \\
\hline & & & & $\mathrm{NV}$ & 15 & 90.6 & 92 & 13.73 & 69 to 109 \\
\hline \multirow[t]{6}{*}{ Reasoning } & \multirow{2}{*}{$\begin{array}{l}\text { WAIS-IV Block } \\
\text { Design }\end{array}$} & SCL & $10(3)$ & VAS & 48 & 8.02 & 8 & 3.1 & 1 to 17 \\
\hline & & & & NV & 12 & 8.92 & 9 & 3.53 & 2 to 16 \\
\hline & \multirow[t]{2}{*}{ WAIS-IV Similarities } & SCL & $10(3)$ & VAS & 48 & 8.13 & 8 & 2.89 & 1 to 15 \\
\hline & & & & NV & 12 & 8.17 & 8.5 & 3.07 & 4 to 13 \\
\hline & \multirow[t]{2}{*}{$\begin{array}{l}\text { WAIS-IV Matrix } \\
\text { Reasoning }\end{array}$} & SCL & $10(3)$ & VAS & 44 & 8.11 & 8 & 2.98 & 2 to 15 \\
\hline & & & & NV & 12 & 9.17 & 8.5 & 3.79 & 4 to 15 \\
\hline \multirow[t]{2}{*}{$\begin{array}{l}\text { Psychomotor } \\
\text { speed }\end{array}$} & \multirow[t]{2}{*}{$\begin{array}{c}\text { D-KEFS TMT } \\
\text { condition } 5 \text { (motor } \\
\text { speed) }\end{array}$} & SCL & $10(3)$ & VAS & 32 & 7.72 & 8 & 3.25 & 1 to 12 \\
\hline & & & & NV & 10 & 7.7 & 9 & 3.02 & 1 to 11 \\
\hline \multirow[t]{6}{*}{$\begin{array}{l}\text { Information } \\
\text { processing }\end{array}$} & \multirow[t]{2}{*}{$\begin{array}{c}\text { D-KEFS CWIT } \\
\text { condition } 1 \text { (color } \\
\text { naming) }\end{array}$} & SCL & $10(3)$ & VAS & 40 & 8.1 & 8 & 2.45 & 3 to 15 \\
\hline & & & & NV & 12 & 8.67 & 9 & 2.81 & 3 to 13 \\
\hline & \multirow[t]{2}{*}{$\begin{array}{l}\text { D-KEFS CWIT } \\
\text { condition } 2 \text { (word } \\
\text { reading) }\end{array}$} & SCL & $10(3)$ & VAS & 40 & 9.28 & 10 & 2.49 & 1 to 13 \\
\hline & & & & NV & 12 & 9.33 & 8.5 & 2.61 & 6 to 13 \\
\hline & \multirow[t]{2}{*}{ RBANS Coding } & Z & $0(1)$ & VAS & 58 & -1.87 & -1.83 & 1.44 & -5.08 to 1.54 \\
\hline & & & & NV & 15 & -1.23 & -0.97 & 1.05 & -3.06 to 0.28 \\
\hline
\end{tabular}




\begin{tabular}{|c|c|c|c|c|c|c|c|c|c|}
\hline & WAIS-IV Symbol & SCL & $10(3)$ & VAS & 49 & 6.86 & 6 & 2.91 & 3 to 18 \\
\hline \multirow{15}{*}{ Attention } & & & & NV & 11 & 7.55 & 7 & 3.17 & 1 to 12 \\
\hline & \multirow[t]{2}{*}{ RBANS Digit Span } & Z & $0(1)$ & VAS & 60 & 0.16 & 0.18 & 1.16 & -2.47 to 2.76 \\
\hline & & & & NV & 16 & 0.03 & 0.18 & 1.14 & -1.88 to 1.46 \\
\hline & \multirow{3}{*}{$\begin{array}{c}\text { D-KEFS TMT } \\
\text { condition } 1 \text { (visual } \\
\text { scanning) }\end{array}$} & & & & & & & & \\
\hline & & SCL & $10(3)$ & VAS & 42 & 7.64 & 9 & 3.3 & 1 to 13 \\
\hline & & & & NV & 10 & 8.7 & 8 & 2 & 6 to 12 \\
\hline & \multirow{2}{*}{$\begin{array}{c}\text { D-KEFS TMT } \\
\text { condition } 2 \text { (number } \\
\text { sequencing) }\end{array}$} & SCL & $10(3)$ & VAS & 43 & 6.72 & 8 & 4.14 & 1 to 14 \\
\hline & & & & NV & 11 & 8.91 & 9 & 1.87 & 6 to 12 \\
\hline & \multirow{2}{*}{$\begin{array}{l}\text { D-KEFS TMT } \\
\text { condition } 3 \text { (letter } \\
\text { sequencing) }\end{array}$} & SCL & $10(3)$ & VAS & 42 & 6.6 & 8 & 3.99 & 1 to 14 \\
\hline & & & & NV & 11 & 7.64 & 9 & 3.75 & 1 to 12 \\
\hline & \multirow{2}{*}{$\begin{array}{l}\text { TEA Telephone } \\
\text { Search }\end{array}$} & SCL & $10(3)$ & VAS & 24 & 5.38 & 5.5 & 2.67 & 1 to 13 \\
\hline & & & & NV & 8 & 7.25 & 7.5 & 3.54 & 2 to 12 \\
\hline & \multirow{3}{*}{$\begin{array}{l}\text { TEA Telephone } \\
\text { Search With } \\
\text { Counting }\end{array}$} & & & & & & & & \\
\hline & & SCL & $10(3)$ & VAS & 24 & 9 & 8 & 4.36 & 4 to 15 \\
\hline & & & & NV & 8 & 9.5 & 9 & 3.63 & 3 to 15 \\
\hline \multirow[t]{10}{*}{ Memory } & \multirow[t]{2}{*}{$\begin{array}{l}\text { RBANS List } \\
\text { Learning }\end{array}$} & Z & $0(1)$ & VAS & 60 & -1.01 & -0.96 & 1.24 & -3.88 to 1.38 \\
\hline & & & & NV & 16 & -0.8 & -0.79 & 1.14 & -2.87 to 0.77 \\
\hline & \multirow[t]{2}{*}{$\begin{array}{l}\text { CVLT-II SF Free } \\
\text { Recall T-Score (list) }\end{array}$} & $\mathrm{T}$ & $50(10)$ & VAS & 44 & 44.02 & 46 & 12.12 & 18 to 66 \\
\hline & & & & NV & 12 & 48.33 & 52 & 11.19 & 20 to 60 \\
\hline & \multirow{2}{*}{$\begin{array}{l}\text { RBANS Immediate } \\
\text { Story Memory }\end{array}$} & Z & $0(1)$ & VAS & 60 & -0.46 & -0.11 & 1.59 & -4.65 to 1.76 \\
\hline & & & & NV & 16 & 0.025 & 0.2 & 1.17 & -1.84 to 1.49 \\
\hline & \multirow{2}{*}{$\begin{array}{l}\text { WMS-IV Logical } \\
\text { Memory I (story) }\end{array}$} & SCL & $10(3)$ & VAS & 48 & 8.02 & 8 & 3.91 & 1 to 15 \\
\hline & & & & NV & 11 & 8.27 & 8 & 5.27 & 1 to 16 \\
\hline & \multirow{2}{*}{$\begin{array}{l}\text { CVLT-II SF Short } \\
\text { Delay Recall (list) }\end{array}$} & Z & $0(1)$ & VAS & 42 & -0.46 & -0.5 & 1.38 & -2.5 to 4 \\
\hline & & & & NV & 11 & -0.18 & -0.5 & 1.38 & -2.5 to 2 \\
\hline
\end{tabular}




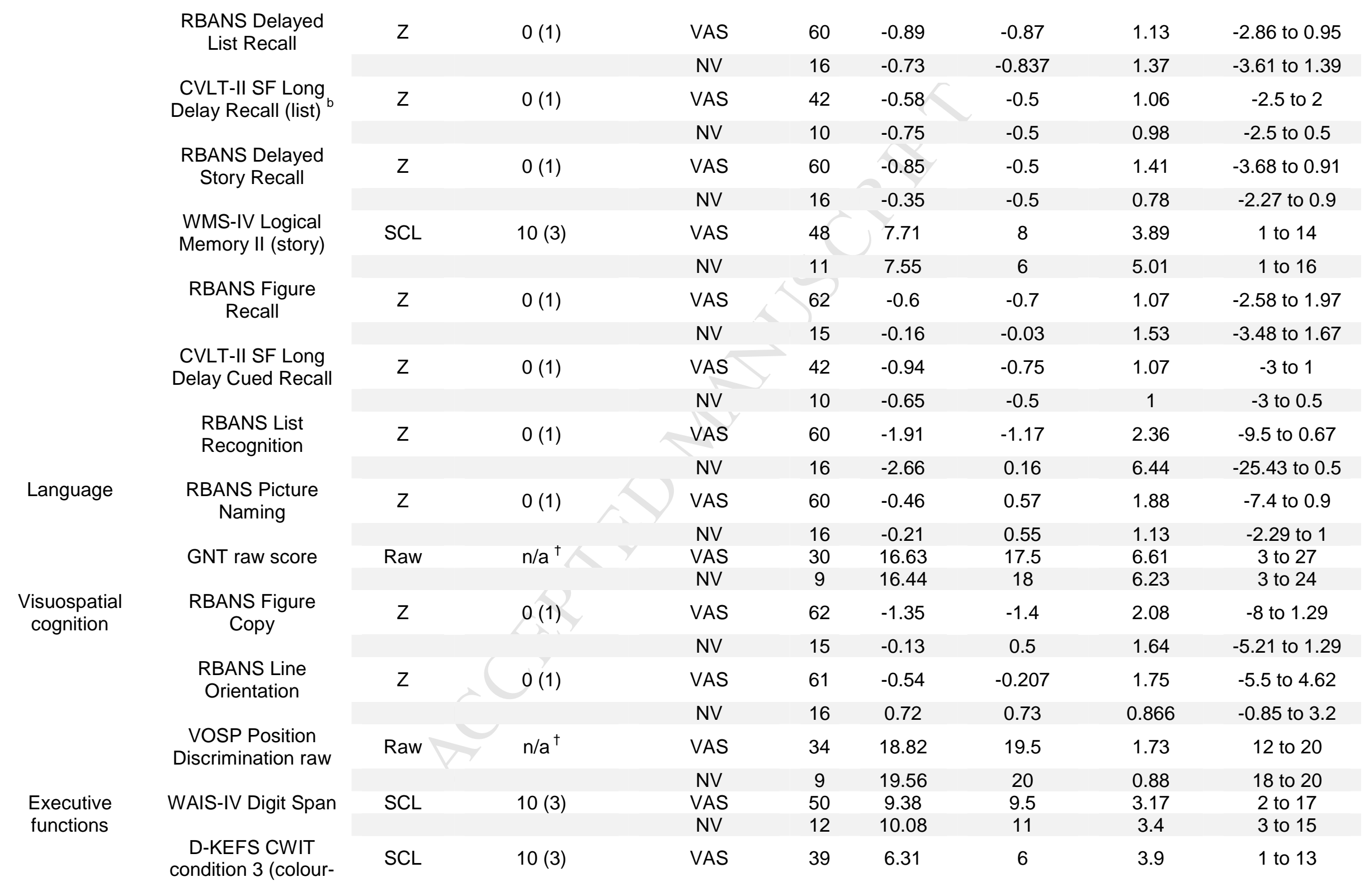




\section{COGNITION AND LOWER LIMB AMPUTATION}

\begin{tabular}{|c|c|c|c|c|c|c|c|c|}
\hline word switching) & & & NV & 11 & 9.45 & 10 & 3.21 & 1 to 13 \\
\hline \multirow[t]{2}{*}{$\begin{array}{l}\text { D-KEFS TMT } \\
\text { condition } 4 \\
\text { (number-letter } \\
\text { switching) }\end{array}$} & SCL & $10(3)$ & VAS & 42 & 5.38 & 5 & 3.83 & 1 to 13 \\
\hline & & & NV & 11 & 7.45 & 9 & 4.34 & 1 to 13 \\
\hline \multirow{2}{*}{$\begin{array}{l}\text { RBANS Semantic } \\
\text { Fluency }\end{array}$} & Z & $0(1)$ & VAS & 60 & -0.84 & -0.87 & 1.22 & -3 to 2 \\
\hline & & & NV & 16 & -1.38 & -1.37 & 1.6 & -5.8 to 0.38 \\
\hline \multirow[t]{2}{*}{$\begin{array}{c}\text { D-KEFS VFT } \\
\text { condition } 1 \\
\text { (category fluency) }\end{array}$} & SCL & $10(3)$ & VAS & 45 & 8.38 & 8 & 3.94 & 3 to 17 \\
\hline & & & NV & 12 & 8.58 & 8.5 & 3.03 & 3 to 13 \\
\hline $\begin{array}{c}\text { D-KEFS VFT } \\
\text { condition } 2 \text { (letter } \\
\text { fluency) }\end{array}$ & SCL & $10(3)$ & VAS & 45 & 8.44 & 8 & 3.84 & 2 to 19 \\
\hline BADS Zoo Map & Raw & $\mathrm{n} / \mathrm{a}^{\dagger}$ & $\begin{array}{l}\text { NV } \\
\text { VAS } \\
\text { NV }\end{array}$ & $\begin{array}{c}12 \\
34 \\
7\end{array}$ & $\begin{array}{l}6.92 \\
\mathrm{n} / \mathrm{a} \\
\mathrm{n} / \mathrm{a}\end{array}$ & $\begin{array}{l}7.5 \\
2 \\
2\end{array}$ & $\begin{array}{l}3.15 \\
\mathrm{n} / \mathrm{a} \\
\mathrm{n} / \mathrm{a}\end{array}$ & $\begin{array}{l}2 \text { to } 12 \\
1 \text { to } 6 \\
1 \text { to } 6\end{array}$ \\
\hline \multirow[t]{2}{*}{$\begin{array}{l}\text { FrSBe self rated } \\
\text { total }\end{array}$} & $\mathrm{T}$ & $50(10)$ & VAS & 25 & 61.04 & 59 & 17.27 & 29 to 99 \\
\hline & & & NV & 10 & 56.7 & 53.5 & 15.42 & 35 to 82 \\
\hline
\end{tabular}

${ }^{\dagger}$ Raw scores: MoCA and GNT each have a possible raw scores ranging from 0 to 30 . VOSP possible scores range from 0-20 (pass $\geq 19$, pass borderline $=18$, fail/impaired $17 / 20$ ). BADS zoo map possible scores range from 1 to 7 (pro-rated ordinal scale). 
